\title{
CUANDO LA LITERATURA Y EL CINE SE CUENTAN
}

\section{LITERATURE AND CINEMA BEING TOLD}

Alicia Canseco Salinero

Universidad Autónoma de Madrid

\section{ABSTRACT}

The film The Fall (2006) by Tarsem Singh and the story "The Man Who Laughs" by J. D. Salinger, included in the famous collection Nine tales (1953) are, however disparate they might look, related, not only in their metafictional construction, but also because of the intradiegesis of their metafictions and the origin of the their development. Similarly, the understanding of the diegetic narratives is, in both cases, essential in the meta-stories, since we perceive them from the point of view of a child who cannot understand the world of adults.

Key words: Metafiction, Literature, Cinematography, Salinger, Tarsem Singh.

\section{RESUMEN}

La película The Fall (2006) de Tarsem Singh y el relato de J. D. Salinger «El hombre que ríe», incluido en la célebre colección de Nueve cuentos (1953), aparentemente tan dispares, están relacionadas no solo por su construcción metaficcional, sino por la intradiégesis de sus metaficciones y lo que provocan que están se desencadenen. Del mismo modo, la 
interpretación de los narratarios diegéticos es, en ambos casos, fundamental en el metarrelato, pues percibimos ambos desde el punto de vista de un niño que no alcanza a entender el mundo de los adultos.

Palabras clave: Metaficción, Literatura, Cine, Salinger, Tarsem Singh.

Fecha de recepción: 9 de diciembre de 2020.

Fecha de aceptación: 19 de diciembre de 2020.

Cómo citar: Canseco Salinero, Alicia (2020): «Cuando la literatura y el cine se cuentan», en Actio Nova: Revista de Teoría de la Literatura y Literatura Comparada, Monográfico 4: 312-327. DOI: https://doi.org/10.15366/actionova2020.m4.014 


\section{INTRODUCCIÓN}

Este estudio se va a centrar en dos obras dispares, en las que, sin embargo, la metaficción opera del mismo modo, esto es, «El hombre que ríe», uno de los brillantes relatos insertos en los Nueve cuentos de Salinger, y la nada despreciable película de Tarsem Singh The Fall. El sueño de Alexandria (2006). Sin embargo, conviene aclarar, antes de proceder al análisis, los conceptos a los que haremos referencia en el presente artículo.

Mucho se ha dicho (y se ha escrito) acerca de la metaficción desde que William H. Gass, aclamado crítico y escritor norteamericano, ya introdujo el término en un artículo que publicó en 1970 en The Philosopher-Critic. Fuera como fuere, lo cierto es que la metaliteratura, en sus múltiples variaciones, ha estado presente desde los albores de la escritura con intención artística y no han faltado numerosos descubridores que la escudriñen y la desentrañen. En primer lugar, debemos precisar que en las obras que se dan cita en este trabajo no solo se halla presente el metarrelato, sino la metaficción, puesto que no nos encontramos ante un personaje cuya narración es real dentro del mundo ficcional en el que se enmarca, en cuyo caso hablaríamos de metaficción relativa (Albaladejo, 2011) o mero metarrelato; antes bien, sendos personajes, que toman el relevo de la narración, inventan historias asimismo ficticias, articulando un segundo nivel literario. Por otro lado, no podemos obviar la acepción según la cual la metaliteratura, y por tanto la metaficción, podría entenderse como una reflexión acerca de la literatura. Así pues, tanto en la película como en el relato el narratario rumia, comenta e influye en la construcción del metarrelato.

Además, no podemos dejar de lado a Bajtin y a su polifonía, ya que la naturaleza metanarrativa y metaficcional de ambas obras es una consecuencia directa de la pluralidad de voces presente en las mismas.

No obstante, no nos detendremos aquí. Si desplazamos nuestra atención de la narración a la recepción comprobaremos que tanto en el texto de Salinger como en la cinta dirigida por Singh se produce una perfectamente estructurada poliacroasis, producto de las múltiples interpretaciones del relato metaficcional (Albaladejo, 2009; 2011; 2013.

Se ha considerado que la metaliteratura encuentra su cauce de expresión adecuado en el siglo $\mathrm{XX}$, pues agotadas ya las fórmulas narrativas, los escritores se arriesgan con innovadoras forman de expresión, explorando la relación entre literatura y creación literaria, entre poética y poesía, entre relato y el hecho de relatar. No resulta extravagante, por tanto, 
que el autor de El guardián entre el centeno empleara la técnica de moda. Así, la historia posmoderna ha propiciado el desarrollo de la metaliteratura, pues ha generado una asombrosa capacidad de interrelación y comunicación entre los distintos ámbitos del saber. En cuanto al séptimo arte, tal y como argumenta el crítico y ensayista Luis Losilla, el metacine alcanza su culminación, claro está, en la vorágine de los años 50, cuando están desapareciendo ya los últimos vestigios del clasicismo y el comentario superficial sobre el mundo del cine puede unirse con toda facilidad a la reflexión sobre lo que muestra y la manera de mostrarlo, sobre su propia condición de reproductor de apariencias y su relación con un mundo pretendidamente real que está pareciéndose cada vez más a aquello que refleja (Losilla, 2004: 17).

La narración cinematográfica, efectivamente, ya era experta en estas lides cuando Singh toma el testigo. Lo veremos a continuación.

\section{THE FALL}

The Fall (2006) es el segundo filme de un avezado realizador que despuntó gracias al virtuosismo visual de su primera cinta, en la que nos introducimos, junto con la actriz de raíces puertorriqueñas Jennifer López, en la mente a ratos retorcida, a ratos tierna, de un asesino en serie. En efecto, La célula (2000) supuso una revolución estilística y una rebeldía contra el cine intimista, los actores creíbles y la ausencia de efectos especiales. No es extraño de un autor que se había curtido rodando anuncios y vídeos musicales, algunos tan célebres, aunque el cineasta se esfuerza por trascenderlo, como el videoclip de «Losing my Religión» de R.E.M. Sin embargo, el director indio Tarsem Singh logra con su segundo largometraje, una coproducción de India, Reino Unido y Estados Unidos, despertar el interés de público y crítica con esta conmovedora historia protagonizada por actores semidesconocidos que impregnan de vida cada fotograma. El realizador descubrió a Lee Pace en un telefilm en el que interpretaba a un transgénero y lo conquistó. Antes de ganar fama para el gran público por ser el actor principal de la serie de culto Pushing Daisies (2007-2009) y participar en la trilogía de El hobbit (2012-2014) filmada por Peter Jackson, el actor americano se pone en la piel de un especialista en escenas de acción que sufre un accidente y acaba perdiendo la movilidad de sus piernas. Tarsem Singh, en una de sus extrañas ocurrencias, hizo creer a todo el elenco, y prácticamente a todo el equipo de producción, que se trataba de un parapléjico real, con el objeto de lograr verosimilitud. Por su parte, Cantica Untaru, la joven 
actriz rumana que le da la réplica, fue escogida debido a una cinta de vídeo en la que la niña se postulaba para el papel y que el director recibió con entusiasmo, a pesar de que él ya había tenido la precaución de enviar a sus directores de casting a varios colegios, en búsqueda de protagonista para su película. Singh tenía muy claro qué edad le interesaba: necesitaba una niña de 4 años, puesto que uno de los encantos del guion se deriva de los malentendidos que se interponen entre la pequeña y el convaleciente. Sin embargo, al no tener Untaru nociones de inglés, transigió con los 6 años. Eso sí, quiso rodar las escenas enseguida, persuadido por la idea de que a los pocos meses sería una niña completamente diferente. La última de sus excentricidades consistió en rodar en 24 países diferentes aprovechando sus contratos de rodajes publicitarios, pues el director aceptaba solamente aquellos trabajos que lo acercaban a los escenarios que quería retratar y se llevaba consigo a todo el equipo.

Estrenada por primera vez en el Festival de Toronto, no llegó a la gran pantalla hasta el año 2008, tras recorrer distintos festivales con suerte desigual. Tan solo un año antes, obtuvo la estatuilla de Mejor Película en el Festival de Cine de Sitges y la mención especial en el Festival Internacional de Cine de Berlín, a pesar de que la crítica tuvo respuestas dispares respecto a la película, que está basada en una anterior, un clásico del cine búlgaro, llamado Yo ho ho (1981) del director Zako Heskija. Tarsem Singh la visionó en la universidad, y desde entonces había querido hacer una revisitación. El título, ciertamente, hace referencia a la famosa canción pirata, puesto que en la cinta un tetrapléjico y un preadolescente traban amistad en el hospital y juntos emprenden una huida (casi modernista) de su decepcionante realidad hacia la ficción de ser bravos corsarios en las Costas del Caribe. Si bien, la premisa es idéntica, la construcción narrativa no es tan compleja en su versión original y, por lo tanto, el juego metaficcional es más pobre. Por otro lado, de la cinta se desprende, acaso, una suave melancolía que difiere de la apasionada violencia de los sentimientos desatados en el remake posterior.

Tras una inversión importante, la película se quedó sin propietario. El propio Tarsem Singh, siempre uniendo fuerzas con su hermano Ajit, había adelantado el dinero para evitar que limitasen sus deseos creativos. Cuando trató de venderla en el Festival de Toronto, donde esperaba recibir una buena crítica del influyente Roger Ebert, amante de La celda, se encontró con la ausencia de este debido a una enfermedad. La crítica fue feroz y nunca logró convencer a ninguna productora. Eso sí, consiguió que Spike Jonze y David Fincher aparecieran en los títulos de crédito iniciales avalando la cinta, ya que ambos realizadores habían colaborado con el indio rodando anuncios al principio de sus carreras. El segundo 
movimiento de la Sinfonía No 7 de Beethoven suena mientras contemplamos en blanco y negro lo que parece ser el malogrado rodaje de una película de vaqueros. Nuestra inmersión, como la del caballo que sacan del río en las imágenes iniciales, es completa.

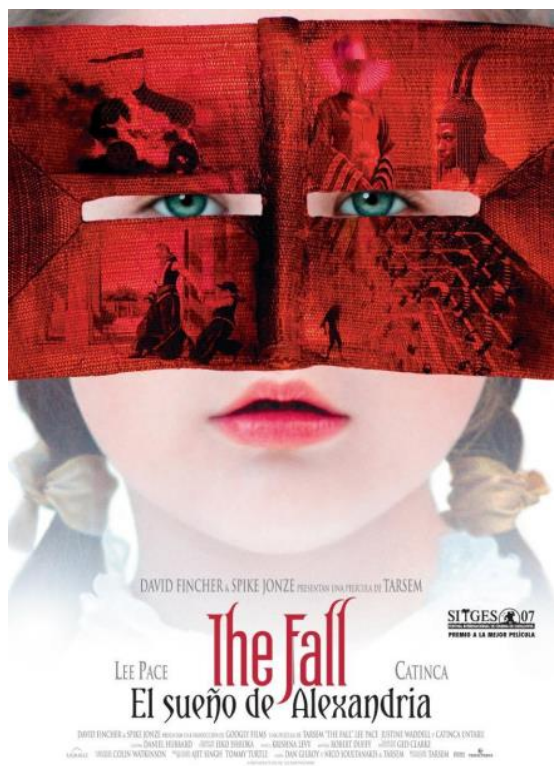

Figura 1: Cártel de la película The Fall

Referencia:

https: / / www.google.es/url?sa=i\&url=https $\% 3 \mathrm{~A} \% 2 \mathrm{~F} \% 2 \mathrm{Fwww}$.filmaffinity.com $\% 2 \mathrm{Fes} \% 2 \mathrm{Ffilm} 698185 . \mathrm{html}$ \&psig=AOvVaw2yCqtHFXGKGJZtkjMT3ekx\&ust $=1607466673817000 \&$ source $=$ images\&cd $=$ vfe\&ved $=0 \mathrm{C}$ A0QjhxqFwoTCPClzZL2vO0CFQAAAAAdAAAAABBS (último acceso: 7/12/2020)

La acción se sitúa en Los Ángeles durante los años 20. Una niña rumana, llamada Alexandria, se encuentra ingresada en un hospital tras la caída sufrida recogiendo fruta en la granja en la que trabaja. Desde el primer momento, Alexandria desempeñará el papel de una suerte de narrador en primera persona y el espectador adoptará su punto de vista. Para el metarrelato esto va a ser fundamental. Así pues, somos testigos de su imponente imaginación cuando ve al asistente de rayos $\mathrm{X}$, que le parece una figura ominosa, de modo que esa será la efigie de lo terrible cuando, más adelante, imagine a los esbirros de Odio. La pequeña se mueve por el hospital buscando algún entretenimiento sin que nadie se fije demasiado en ella. He ahí que entabla amistad con Roy Walker, un especialista en escenas de acción que ha sido internado después de un accidente. El joven llama su atención señalando que es tocaya de Alejandro Magno y le cuenta una de sus míticas anécdotas. Las palabras de Roy cobran vida y somos testigos de la historia que narra el joven pero que Alexandria interpreta a su 
manera. Por eso, Alejandro primero está montado a caballo entre unas ruinas y después de las pertinentes aclaraciones de Roy se encuentra en el desierto. Tal y como hemos anticipado al referimos al técnico de Rayos X, elementos de la diégesis se introducen en la intradiégesis. Otro ejemplo sería el mensaje con pequeños recortes en papel interceptado por Roy que Alexandria le dirige a la enfermera Evelyn. La niña escucha las conversaciones ente adultos, pero no las entiende. Así, cuando otro especialista con una pierna ortopédica va a visitar a Roy, la pequeña lo confunde con un pirata. El cuentacuentos ha logrado la atención de la niña. Este es el punto de partida del metarrelato. El convaleciente introduce a los personajes de su narración ficcional atribuyéndoles epítetos como si se tratase de un poema épico, con golpes efectistas, cual vocalista que presenta a los miembros de su banda de rock. El grupo está compuesto por un esclavo negro, un experto en explosivos, un indio que cuando se pone nervioso se toca una ceja, y un trasunto de Charles Darwin, que siempre va acompañado por su fiel mono. Todos ellos, liderados por el bandido enmascarado, tienen algo en común: detestan al gobernador Odio, quien, por cierto, es de origen español. Todos ellos, además, tienen la apariencia y atributos de personas que rodean a Alexandria en su vida cotidiana. Al principio el bandido tiene los dientes separados y acento rumano, ya que Roy intenta que el protagonista le recuerde a la niña a su padre, asesinado, en palabras de Alexandria, por «gente enfadada». Después, la pequeña vuelve a cambiar las reglas del juego. $\mathrm{Y}$ es así como ella interviene en la historia, interpretando y modificando lo que cuenta el narrador. El protagonista deja de hablar con acento rumano y se convierte en su nuevo héroe, su amigo Roy. En un alarde de virtuosismo narrativo, los chamanes les indican el camino que han de seguir mezclando lugares exóticos con los molinos manchegos, la Torre Eiffel, el Coliseo o la Estatua de la Libertad. De este modo, en un doble salto mortal la intradiégesis y la extradiégesis se mezclan. En realidad, el relato interno es un reflejo de lo que está ocurriendo en la historia marco. El actor impregna sus sentimientos al relato, de modo que este se va volviendo cada vez más oscuro a medida que crecen en él los deseos suicidas. La estratagema de aprovecharse de la niña para conseguir morfina no resulta como esperaba. Deprimido por haberse convertido en un tullido y ser abandonado por su novia, quien ahora está en brazos del protagonista de la película que estaba rodando, no es capaz de hallar ninguna esperanza. Por ese motivo, el cuento avanza trágicamente con la muerte sucesiva de los miembros del grupo y la traición de la enfermera Evelyn, en la que proyecta Alexandria a la despiadada exnovia de Roy. Si bien el desenlace está abocado a la destrucción del 
protagonista (en sendos mundos ficcionales), el afecto de la niña conmueve a Roy y consigue finalmente que el bandido y él mismo permanezcan a salvo.

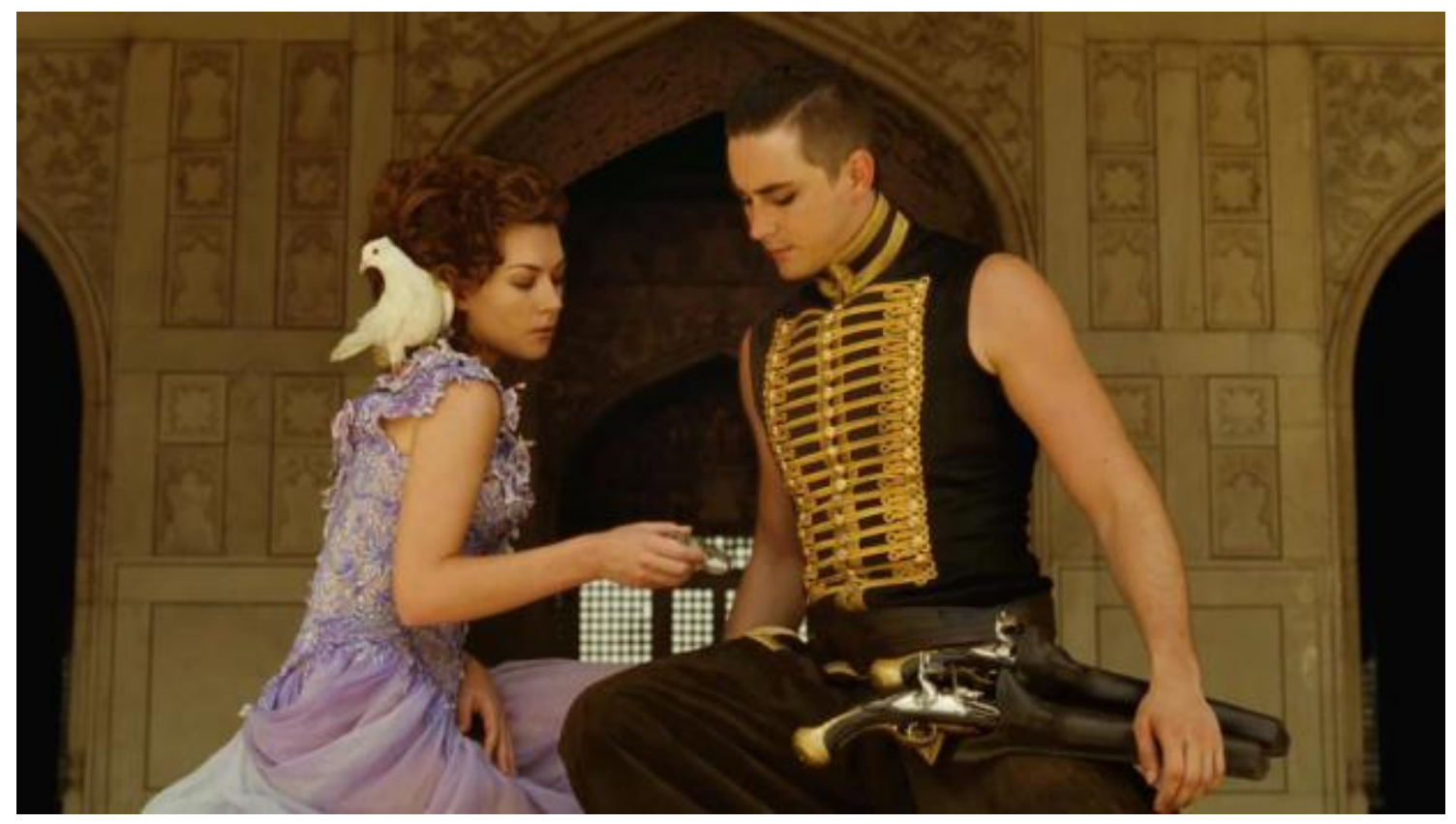

Figura 2: Fotograma de la película The Fall. Referencia:

https://www.google.es/url?sa=i\&url=https $\% 3 \mathrm{~A} \% 2 \mathrm{~F} \% 2 \mathrm{Fwww}$. abc.es $\% 2 \mathrm{Fplay} \% 2 \mathrm{Fpelicula} \% 2 \mathrm{Fth}$ e-fall-el-sueno-de-alexandria-

25744\%2F\&psig $=$ AOvVaw2yCqtHFXGKGJZtkjMT3ekx\&ust $=1607466673817000 \&$ source $=$ ima ges\&cd=vfe\&ved=0CA0QjhxqGAoTCPClzZL2vO0CFQAAAAAdAAAAABD0AQ (última consulta: 7 de diciembre de 2020)

Con unas pocas pinceladas, estamos en condiciones de entender cómo se construye la metaficción de la película, que, por añadidura, tiene pequeñas dosis de metacinematografía, en tanto que la historia gira en torno al accidente sufrido por un extra del cine, producido en el rodaje de un clásico hollywoodiense.

\section{EL HOMBRE QUE RÍE}

Salinger muestra en «El hombre que ríe» un buen ejemplo de la teoría que venimos manejando. Así, encontramos a un joven que inventa y engrosa un cuento para entretener, durante los trayectos en autobús, a los chicos del equipo de béisbol que él entrena. No solo 
eso, sino que, al igual que el cuentacuentos de The Fall, permuta el relato en función de su estado de ánimo; en concreto, según cómo le van las cosas con su novia.

«El hombre que ríe» fue publicado por primera vez en 1949 en el periódico The New Yorker, antes de formar parte de la magnífica colección de los Nueve cuentos de Salinger. Tiene sentido pensar que también en este caso la obra se reelabora a partir de una anterior y que el relato hace referencia a la novela homónima de Victor Hugo, puesto que en ambos textos el protagonista es un ser desfigurado, condenado a sonreír eternamente. Sin embargo, según French, Salinger no tuvo que haber leído necesariamente la novela del romántico francés. Por el contrario, «El hombre que ríe» podría ser una fundición de distintas fuentes, sobre todo historias de su infancia (French, 1976).

El narrador empieza a explicar quién era antes de comenzar el relato para dar razones de su confidencialidad como testigo de los sucesos. La primera persona confiere a la narración un tono confesional que hará que nos identifiquemos con el protagonista. De este modo, desde el comienzo parece que nos quiere introducir en su mundo, para que veamos la realidad tal y como él la ve, para que entendamos sus acciones, para que compartamos sus sentimientos. Como si fuera un Lázaro de Tormes justificando su derrota, ese ponernos en antecedentes opera el clásico captatio benevolentia. La aportación de datos y cifras refuerza en el relato la pretendida verosimilitud. Se presenta así a John Gedsudski, el Jefe. La admiración por parte del narrador testigo es evidente y demuestra que corresponde a los más pequeños alabar las virtudes de los mayores sin percatarse de sus defectos e incoherencias. Resume la opinión que le merece su entrenador en pocas palabras: «Era un joven tranquilo, sumamente tímido, de veintidós o veintitrés años, estudiante de derecho en la Universidad de Nueva York, y una persona memorable desde cualquier punto de vista» (Salinger, 2006: 61). A continuación, alude a las extraordinarias cualidades deportivas del entrenador. En el siguiente párrafo el narrador empieza a dar notas displicentes acerca del protagonista de su relato, dejándonos ver que se trataba solo de la impresión de un niño. Cuando terminaba la jornada, el Jefe contaba a los comanches, durante el trayecto en el que conducía el autobús de regreso a casa, el que era para ellos el cuento más interesante y deleitoso, «El hombre que ríe». Tras esta introducción el narrador pasa a referir lo anteriormente relatado introduciéndose en un juego metaficcional.

$\mathrm{El}$ «hombre que ríe» era un hijo de unos misioneros en china que había sido raptado por una banda de criminales, quienes deforman al pequeño para vengarse de sus padres, ya que no habían querido pagar el rescate debido a sus «convicciones religiosas». El metarrelato 
produce unas curiosas manifestaciones por parte del narrador, de modo que este reconoce cómo imaginaba la narración del entrenador, interpretando sus palabras y completando con inferencias los vacíos del texto. En un determinado momento admite: «Cuando el "hombre que ríe" respiraba, la abominable, siniestra abertura debajo de la nariz se dilataba y contraía (yo la veía asî) como una monstruosa ventosa» (Salinger, 2006: 63). Ciertamente, el paréntesis es significativo. En un retorcido giro de los acontecimientos el niño deforme se convierte en hijo adoptivo de los bandidos. Para ocultar su rostro el «hombre que ríe» tapaba su boca con una máscara de pétalos de amapola que despedía un penetrante olor a opio. El narrador interviene de vez en cuando para recordarnos que el «hombre que ríe» se trata de una invención y no es la realidad en la que él, también personaje del relato marco, está inmerso. En este momento empezamos a vislumbrar las semejanzas entre el joven entrenador y el bandido. Ambos son personas que, aunque son inteligentes y muy válidas, están aisladas. El personaje de Salinger se convierte en bandido profesional, si bien destaca en él un sentimiento de piedad que resulta muy atractivo al narrador. Una vez más, vierte esta reflexión en un paréntesis del texto. Por supuesto, nuestro bandido tiene un enemigo: Dufarge, detective que trata de atraparlo, aunque nunca lo consigue. Esto ocurre cuando empieza a actuar en París. En el momento en que empieza a ser un delincuente poderoso, se rodea de cuatro amigos, tan extravagantes como él. El conjunto lo forman un lobo, un enano, un gigante y una chica euroasiática que está desesperadamente enamorada de él.

La historia cala tanto en las jóvenes mentes de los jugadores del equipo de béisbol, quienes se hacen llamar los comanches, que enseguida empiezan a ilusionarse con la idea de ser ellos mismos extraordinarios bandidos. El narrador nos refiere hasta qué punto el relato del Jefe penetró en él:

No digo que lo vaya a hacer, pero podría pasarme horas llevando al lector -a la fuerza, si fuere necesario- de un lado a otro de la frontera entre París y China. Yo acostumbro a considerar al "hombre que ríe" como una especie de superdistinguido antepasado mío [...]. Y esta ilusión resulta verdaderamente moderada si se la compara con la que abrigaba hacia 1928, cuando me sentía, no solamente descendiente directo del "hombre que ríe", sino además su único heredero viviente (Salinger, 2006: 65).

Las cosas empiezan a complicarse cuando hace aparición la chica del Jefe, Mary Hudson. Mary es el elemento disruptor, la extraña que desestabiliza el equilibrio del grupo. Aquella que consigue que las cosas que pueden ser de otra manera sean de otra manera. A los chicos no les gusta su presencia, puesto que auguran que va a destruirlos. Sin embargo, 
contra todo pronóstico, Mary se integra dentro del grupo y se revela como una estupenda bateadora.

Un día de abril, los comanches se acercan como tantas veces a recoger a Mary, mas esta no aparece. Mientras esperan, John Gedsudski les narra un nuevo episodio del «hombre que ríe». En esta ocasión, Dufarge tiende una trampa al héroe. En este momento, el Jefe se interrumpe e inicia su recorrido hasta el parque sin su chica. Más adelante descubren a Mary en el parque, pero el narrador siente que algo no va bien entre ellos. La relación entre relato y metarrelato, es evidente. Cuando las cosas no le van bien al entrenador de los comanches el «hombre que ríe» sufre. El abandono de Mary supone una muerte lenta y trágica para el bandido. El detective alcanza el corazón del delincuente pero él logra sobrevivir y causarle la muerte. Sin embargo, está atrapado en alambre de espino y cuando, por fin, consigue que el enano Omba vaya en su auxilio, está a punto de morir. Al enterarse de que Dufarge ha asesinado a Ala Negra, su fiel lobo, no tiene ya más ganas de vivir. En un último gesto dramático el «hombre que ríe» se deshace de su máscara.

\section{THE FALL \& El HOMBRE QUE RÍE}

A estas alturas, ya nos hemos convencido de la relación existente entre la construcción metaficcional de los discursos de J. D. Salinger y Tarsem Singh. Pero no es, ni mucho menos, el único paralelismo.

Como ya hemos ido señalando a medida que repasábamos el cuento de Salinger, el narrador es interno. La voz que nos guía a través de los acontecimientos del relato no es, no obstante, la del protagonista de los mismos, sino que se trata de un narrador testigo. Tiene sentido que Salinger escoja esta perspectiva para su narración, puesto que el autor concibe una realidad subjetiva, caleidoscópica y cambiante que nos remite una vez más al concepto de poliacroasis. Del mismo modo, la perspectiva de The Fall es la de la joven protagonista. Vemos el mundo a través de sus ojos y el relato de su compañero de hospital cobra vida desde su fecunda imaginación.

Por añadidura, tanto el cuento como el filme reflejan la extrañeza de un niño ante las convenciones sociales del adulto. El narrador de «El hombre que ríe» nos presenta el texto como una suerte de relato confesional de un suceso decisivo en la infancia del narrador, quien es un personaje infidente. A pesar de la seguridad que este demuestra en sus recuerdos, 
no podemos darle demasiada credibilidad. Por un lado, los hechos recordados no siempre son verdaderos, puesto que la memoria tantas veces traiciona, engaña y distorsiona. Por otro lado, un niño, desde su mirada limpia hacia el mundo, no es capaz de entender los convencionalismos y rituales de los adultos. Para French, hay dos posibles interpretaciones del relato. En primer lugar, aquella que nos da a entender que la literatura es una especie de redención, de catarsis. Por otro lado, podría ser una muestra de cómo la vida influye en la literatura y nuestras experiencias vitales configuran lo que pensamos $y$, por tanto, lo que escribimos. Asimismo, Alexandria se rebela contra la devoradora tristeza de su amigo y le insta a que no siga amando a alguien que le ha traicionado. Con dulces reproches y entre lágrimas, la pequeña consigue que el convaleciente supere lo que para Alexandria es un asunto sencillo. A veces, los niños ven las cosas con una claridad pasmosa. En ambos casos, además, la mujer actúa como una femme fatale, puesto que ella desencadena el conflicto narrativo provocado por el desengaño amoroso que sufren los narradores internos.

Por último, por si todo lo anterior no fuera suficiente, los metarrelatos de «El hombre que ríe» y The Fall también se parecen. Los dos suceden en un tiempo mítico y en lugares exóticos. En ambos el protagonista es un bandido que cubre su rostro con una máscara, y un grupo de personajes excéntricos lo acompañan. Tanto en la película como en el cuento los personajes tienen mascotas cuasi humanas, importantes para ellos. La única diferencia sustancial es que la producción cinematográfica tiene un clímax emocionante, pero un final azucarado, mientras que el relato de Salinger, deja un regusto amargo. Amargo, aunque delicioso. 


\section{BIBLIOGRAFÍA}

Albaladejo Mayordomo, Tomás (2009): «Retórica de la comunicación y retórica en sociedad», en Beristáin, Helena; Gerardo Ramírez Vidal (ed.) (2009): 39-58.

Albaladejo Mayordomo, Tomás (2011): «La ficción es la realidad. Metarrelato y metaficción en Llámame Brooklyn de Eduardo Lago», en Calvo Revilla, Ana; Juan Luis Hernández Mirón; María del Carmen Ruiz de la Cierva; Gonzalo Hidalgo Bayal (ed.) (2011): 23-30.

Albaladejo Mayordomo, Tomás (2013): «Retórica cultural, lenguaje retórico y lenguaje literario», Tonos Digital. Revista Electrónica de Estudios Digitales, 25: http://www.um.es/tonosdigital/znum25/secciones/estudios-03retorica_cultural.htm (último acceso: 22/5/2017).

Brombert, Victor (1988): The bidden reader, Londres, Harvard University Press.

Carrasco, Hugo (1982): «Introducción al estudio del narratario», en Documentos lingüísticos y literarios, 8: http://www.humanidades.uach.cl/documentos_linguisticos/docannexe.php?id=4 34 (último acceso: 10/5/2017).

Conde, Juan Luis (2001): El segundo amo del lenguaje, Madrid, Debate.

Ebert, Roger (2008): «Tarsem and the legend of "The Fall"» en RogerEbert.com: https://www.rogerebert.com/interviews/tarsem-and-the-legend-of-the-fall (último acceso: 08/5/2017).

Eco, Umberto (1987): Lector in fabula: la cooperación interpretativa en el texto narrativo, traducción española de Ricardo Pochtar, Barcelona, Lumen.

French, Warren (1976): J. D. Salinger, Boston, Twayne Publishers.

Genette, Gerard (1989): Palimpsestos. La literatura en segundo grado, traducción española de Celia Fernández Prieto, Madrid, Taurus.

Goldstein, Patrick (2007): «A "Fall" no one wants to take» en Los Angeles Times: https://www.latimes.com/archives/la-xpm-2007-jun-26-et-goldstein26-story.html (último acceso: 08/12/2020).

Gómez Alonso, Juan Carlos (2017): «Intertextualidad, interdiscursividad y retórica cultural», Tropelías. Revista de Teoría de la Literatura y Literatura Comparada, número extraordinario 
https://papiro.unizar.es/ojs/index.php/tropelias/article/download/2104/1909 (último acceso: 7/12/2020).

Hamilton, Ian (1988): En busca de J. D: Salinger: una vida de escritor, Madrid, Mondadori.

Harvey, Dennis (2006): «The Fall Review» en Variety: https://web.archive.org/web/20091202160505/http://www.variety.com/review /VE1117931644.html?categoryid=31\&cs=1 (fecha del último acceso: 08 de diciembre de 2020).

Hugo, Victor (2016): El hombre que ríe, traducción española de Víctor Goldstein, Valencia, Pre-Textos.

IMDb: «The Fall (2006) - Awards»: https:/ /www.imdb.com/title/tt0460791/ (último acceso: $10 / 12 / 2020)$.

IMDb: «Lee Pace»: https://www.imdb.com/name/nm1195855/(último acceso: $10 / 12 / 2020)$.

Jauss, Hans Robert (1992): Experiencia estética y hermenéutica literaria: ensayos en el campo de la experiencia estética, traducción española de Jaime Siles; Ela Ma Fernández-Palacios, Madrid, Taurus.

Kermode, Frank (1983): El sentido de un final, traducción española de Lucrecia Moreno de Sáenz, Barcelona, Gedisa.

Lee, Nathan (2008): «Movie Review - The Fall» en The New York Times: https://web.archive.org/web/20091202160505/http://www.variety.com/review /VE1117931644.html?categoryid=31\&cs=1 (fecha del último acceso: 08 de diciembre de 2020).

Lewis, C. S. (2000): La experiencia de leer: un ejercicio de crítica experimental, traducción española de Ricardo Pochtar, Barcelona, Alba.

Losilla, Carlos (2004): «Tautología y Metacine», Revista Vértigo, 10: 16-21.

Martínez Fernández, José Enrique (2001): La intertextualidad literaria: (base teórica y práctica textual), Madrid, Cátedra.

Mayoral, José Antonio (ed.) (2015): Estética de la recepción, Madrid, Arco/Libros.

Morón Hernández, Luis (2006): «Estética de la recepción literaria»: http://www.une.edu.pe/dev/erl.pdf (fecha del último acceso: 08 de mayo de 2017).

Prince, Gerald (1982): Narratology: the form and functioning of narrative, Berlín, Mounton Publishers. 
Prince, Gerald (1991): A Dictionay of Narratology, Aldershot, Scolar Press.

Redondo, Rubén (2014): El original. Yo Ho Ho (Zako Heskija) en cinemaldito.com: https://www.cinemaldito.com/el-original-yo-ho-ho-zako-heskija/ (último acceso: 10/12/2020).

Robinson, Tasha (2008): «Interviews: Tarsem» en The A. V. Club: https://web.archive.org/web/20081216023910/http://www.avclub.com/conten t/interview/tarsem (último acceso: 8/12/2020).

Rodríguez Pequeño, Javier (1995): Ficción y géneros literarios, Madrid, Ediciones de la Universidad Autónoma de Madrid.

Rodríguez Pequeño, Javier (2008): Géneros literarios y mundos posibles, Madrid, Eneida.

Rothe, Arnold (2015): «El papel del lector en la crítica alemana contemporánea», en Mayoral, José Antonio (ed.) (2015): 13-30.

Salinger, Jerome David (2006): Nueve cuentos, traducción española de Elena Rius, Madrid, Alianza Editorial.

Singh, Ajit; Tommy Turtle; Tarsem Singh (productores) y Singh, Tarsem (director), (2006), The Fall [Cinta cinematográfica], India, Reino Unido y Estados Unidos: Radical Media Absolute Entertainment.

Warning, Rainer (ed.) (1989): Estética de la recepción, traducción española de Ricardo Sánchez Ortiz de Urbina, Madrid, Visor.

Warning, Reiner (1989): «La estética de la recepción en cuanto pragmática de la historia de la literatura», en Warning, Rainer (ed.) (1989): 13-34.

Wise, Damon (2008): «Final Fantasy: Damon Wise meets Tarsem Singh, director of the Fall» en The Guardian:

https://www.theguardian.com/film/2008/oct/04/fall.tarsem.singh (último acceso: 8/12/2020). 
SOBRE LA AUTORA

\section{Alicia Canseco Salinero}

Licenciada en Filología Hispánica por la Universidad Complutense de Madrid, está realizando la tesis doctoral en el programa de doctorado en Estudios Artísticos, Literarios y de la Cultura en la Universidad Autónoma de Madrid.

Contact information: correo electrónico: canseco_alicia@hotmail.com 